\title{
Impact of Laboratory Methods and Gene Targets on Detection of Streptococcus pneumoniae in Isolates and Clinical Specimens
}

\author{
Mehrdad Mosadegh ${ }^{1}$, Rozita Asadian², Amir Darb Emamie ${ }^{1}$, \\ Mohammadreza Rajabpour ${ }^{1}$, Elmira Najafinasab ${ }^{3}$, \\ Mohammad Reza Pourmand ${ }^{* 1}$, Mohammad Azarsa*3
}

\begin{abstract}
Background: Timely identification of Streptococcus pneumoniae infections can lead to a decrease in mortality rates. Differentiation of $S$. pneumoniae from other similar species using traditional culture-based and molecular methods is problematic. In this study, we assessed the efficacy of identifying the $b l p A$ and $l y t A$ for the detection of $S$. pneumoniae from isolates and various clinical samples using molecular methods.

Methods: A total of 440 clinical samples were collected from patients with suspected invasive pneumococcal infections during February 2016 to October 2018. Biochemical tests were used to confirm the dubious colonies on 5\% sheep blood agar. Fifty-seven confirmed isolates, 57 culture-positive samples, and 57 culture-negative samples were analyzed for the presence of $b l p A$ and $l y t A$ using both conventional and real-time PCR.

Results: All the isolates and culture-positive samples were positive for $b l p A$ and lytA by both PCR methods. Of the 57 culture-negative samples, conventional and real-time PCR amplified $b l p A$ from six and two samples, and $l y t A$ from seven and two samples, respectively.

Conclusions: The specificity of real-time PCR assay was significantly higher than that of conventional PCR for the identification of S. pneumoniae. In addition, it is suggested that respiratory secretions are not suitable specimen for direct diagnosis of pneumococcal infections.
\end{abstract}

Keywords: $b l p A$, Molecular Detection, Molecular Diagnostic Techniques, Real-Time Polymerase Chain Reaction, Streptococcus pneumoniae.

\section{Introduction}

Invasive pneumococcal diseases (IPD), which include bacterial pneumonia, meningitis, and sepsis in children and seniors (1), are caused by $S$. pneumoniae and are major infectious diseases. A recent survey estimated that $S$. pneumoniae was responsible for 393,000 pneumonia-related deaths in children under age five in 2015 (2). Nasopharyngeal colonization by $S$. pneumoniae frequently leads to IPD and this organism is a reservoir of genes for transmission to other related species (3). Hence, correct diagnosis of pneumococcal infections is critical to understanding the potential for disease in a community-based population and providing timely treatment.

Pneumococcal isolates are heterogeneous and have the ability for genetic alteration and adaptation. These abilities result in the protection of bacteria in multiple conditions. Antibioticresistant strains have emerged due to genetic 
mutations and are spreading. Moreover, the current vaccine, which protects against some serotypes, may not be effective against emerging vaccine-escape strains (4).

Culture-based methods are the gold standard for the identification of $S$. pneumoniae from clinical specimens (5). However, these methods have some deficiencies, including diminished sensitivity due to antibiotic therapy, activation of autolysins during sample transportation, and the emergence of optochin-resistant strains, which can give falsenegative results $(6,7)$. Therefore, the evaluation of new methods for rapid and reliable identification is an important research area. In recent years, several genes, including ply and lytA, have been targeted for the detection of pneumococci by molecular methods. However, it has been shown that the use of these genes can give false-positive and falsenegative results (8). Consequently, the evaluation of new conserved genes is crucial for the detection of $S$. pneumoniae in clinical specimens. In the present study, we assessed the sensitivity and specificity of the $b l p A$ as a conserved gene for the detection of $S$. pneumoniae from isolates and clinical samples and compared it with the lytA gene (lytA), as recommended by the World Health Organization (WHO) (9).

\section{Materials and methods \\ Clinical isolates}

From February 2016 through October 2018, 440 clinical specimens were collected from patients with clinically suspected invasive pneumococcal infections. Clinical specimens were obtained from blood, cerebrospinal fluid (CSF), tracheal aspirates, ascites, pleural aspirates, bronchoalveolar lavage (BAL), sputum, sinus secretions, and eye infections. These samples were inoculated onto 5\% sheep blood agar plates and incubated at $37{ }^{\circ} \mathrm{C}$ in $5 \% \mathrm{CO}_{2}$ for $24 \mathrm{hr}$. The $S$. pneumoniae colonies were identified using standard conventional tests including gram staining, catalase, bile solubility, and optochin (MAST, UK) sensitivity tests. The isolates were preserved in trypticase soy broth (Merck, Germany) with $10 \%$ glycerol at $-70{ }^{\circ} \mathrm{C}$ for further studies (10).

\section{DNA extraction}

Genomic DNA was extracted from isolates and clinical samples using a DNeasy Blood \& Tissue kit (Qiagen, Germany) according to the manufacturer's instructions.

\section{PCR assay}

All of the isolates, 57 culture-positive, and 57 culture-negative samples were analyzed for the presence of $b l p A$ and $l y t A$ with the primers shown in Table 1. Culture-negative samples were randomly chosen from 383 specimens, including sputum $(\mathrm{n}=17)$, blood $(\mathrm{n}=13), \mathrm{BAL}$ $(n=9)$, tracheal aspirates $(n=7), \operatorname{CSF}(n=6)$, synovial fluid $(n=3)$, and ascitic fluid $(n=2)$. PCRs were performed separately for $l y t A$ and blpA with hot start Taq master mix kit (Sinaclon, Iran) that contained $12.5 \mu \mathrm{l}$ of $2 \mathrm{x}$ hot start Taq master mix (including $0.4 \mathrm{mM}$ of each dNTP, $3 \mathrm{mM} \mathrm{MgCl} 2,0.08 \mathrm{U} / \mu 1$ Taq DNA polymerase), $1 \mu \mathrm{l}$ of each primer $(10 \mathrm{pmol} / \mu \mathrm{l}), 2 \mu \mathrm{l}$ of DNA, and $11.5 \mu \mathrm{l}$ of $\mathrm{ddH}_{2} \mathrm{O}$. The PCR program included an initial denaturation at $94{ }^{\circ} \mathrm{C}$ for 5 min, 35 amplification cycles of $94{ }^{\circ} \mathrm{C}$ for $30 \mathrm{sec}$, $58{ }^{\circ} \mathrm{C}$ for $35 \mathrm{sec}$, and $72{ }^{\circ} \mathrm{C}$ for $1 \mathrm{~min}$, with a final extension at $72{ }^{\circ} \mathrm{C}$ for $10 \mathrm{~min}$. The PCR products were electrophoresed in $1 \%$ agarose gels (Biotium Inc. USA).

Table 1. PCR primer sequences.

\begin{tabular}{llll}
\hline Primers & \multicolumn{1}{c}{ Sequences } & Product sizes (bps) & Reference \\
\hline \multirow{2}{*}{$b l p A$} & F: 5'-GCTACTAGCGGTCTTGATGTC-3' $^{2}$ & 131 & \multirow{2}{*}{ This Study } \\
\hline \multirow{2}{*}{ lyt 5'-AGAACAATGACACGGTTGGTT-3' $^{\prime}$} & F:5'-ACGCAATCTAGCAGATGAAGCA-3' & 319 & \multirow{2}{*}{$(11)$} \\
\hline
\end{tabular}

\section{Real-time PCR assay}

The real-time PCR assays targeting blpA and lytA were performed separately with Taq Man probe and HiFi hot start master mix in a final volume of $20 \mu \mathrm{l}$ containing $4 \mu \mathrm{l}$ of master mix, $1 \mu \mathrm{l}$ of each primer $(10 \mathrm{pmol} / \mu \mathrm{l})($ Table 2$), 1 \mu \mathrm{l}$ of probe (10 $\mathrm{pmol} / \mu \mathrm{l}), 2 \mu \mathrm{l}$ of DNA and $11 \mu \mathrm{l}$ of $\mathrm{ddH}_{2} \mathrm{O}$. The S. pneumoniae strain ATCC 49619 was included as a control. This method was used for the isolates, culture-positive $(\mathrm{n}=57)$, and our selected culture-negative samples $(\mathrm{n}=57)$. The 
amplification program is shown in Table 3. To determine the sensitivity and limit of detection (LOD), we initially prepared serial 10-fold dilutions of 0.5 McFarland standard of $S$. pneumoniae. The dilution series was inoculated on sheep blood agar plates and colonies were counted (in CFU). A dilution series of purified DNA $\left(10^{7}\right.$ CFU $)$ was prepared and the concentration of primers and probes optimized following DNA amplification. The curve of threshold cycle $(\mathrm{Ct})$ values was plotted based on the number of bacteria.

Table 2. Real-time PCR primer and probe sequences.

\begin{tabular}{|c|c|c|}
\hline $\begin{array}{l}\text { Primers and } \\
\text { probes }\end{array}$ & Sequences & References \\
\hline blpA primers & $\begin{array}{l}\text { F: 5'-GCTACTAGCGGTCTTGATGTC-3' } \\
\text { R: 5'-AGAACAATGACACGGTTGGTT-3' }\end{array}$ & This Study \\
\hline blpA probe & 5'-FAM-AGCCCATCGTCTCAGTATAGCCGAACG-3'-BHQ1 & This Study \\
\hline lytA primers & $\begin{array}{l}\text { F:5'-ACGCAATCTAGCAGATGAAGCA-3' } \\
\text { R:5'-TCGTGCGTTTTAATTCCAGCT-3' }\end{array}$ & (12) \\
\hline lytA probe & 5'-FAM-TGCCGAAAACGCTTGATACAGGGAG-3-'BHQ1 & (12) \\
\hline
\end{tabular}

Table 3. Temperature program for blpA and lytA real-time PCR.

\begin{tabular}{lccc}
\hline Step & Temperature & Time & Cycle No. \\
\hline Initial Denaturing & $95^{\circ} \mathrm{C}$ & $10 \mathrm{Min}$ & 1 \\
Denaturing & $95^{\circ} \mathrm{C}$ & $15 \mathrm{Sec}$ & 40 \\
Annealing and Extension & $60^{\circ} \mathrm{C}$ & $60 \mathrm{Sec}$ & 40 \\
\hline
\end{tabular}

\section{Results}

\section{Bacterial isolates}

Fifty-seven strains of pneumococci were isolated from 440 clinical samples using culture-based methods, including gram staining, bile solubility, and optochin susceptibility tests. Two isolates were optochin-resistant, and identified as $S$. pneumoniae strains by molecular methods.

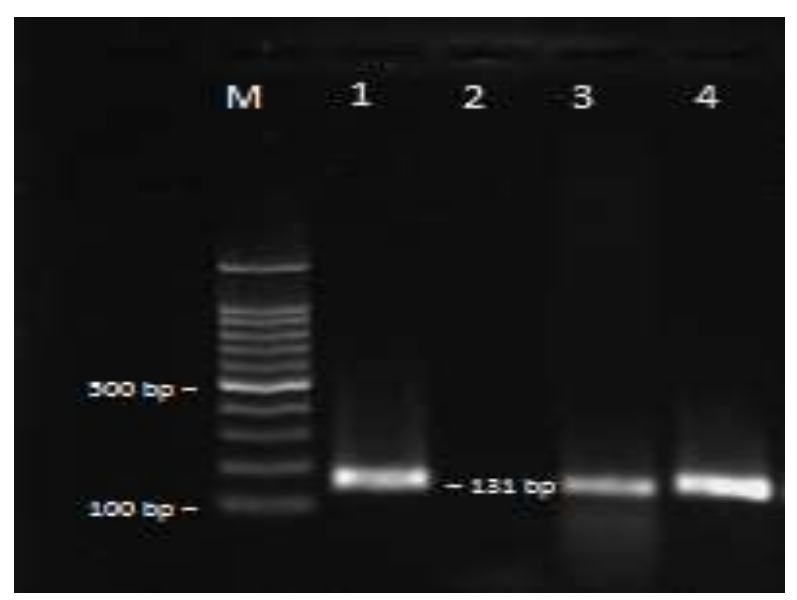

Fig. 1. Amplification of $b l p A$ from $S$. pneumoniae. M: DNA marker (100 bps); 1: positive control; 2: negative control; 3 and 4: samples.

\section{Conventional PCR assay}

By conventional PCR, all the isolates and culturepositive specimens were positive for $l y t A$ and blpA, while six $(10.5 \%)$ and seven $(12.3 \%)$ of the culture-negative samples were positive for $b l p A$ and $l y t A$, respectively (Figs. 1 and 2). Moreover, two of these samples were positive for both. All the PCR-positive, culture-negative samples were from respiratory secretions.

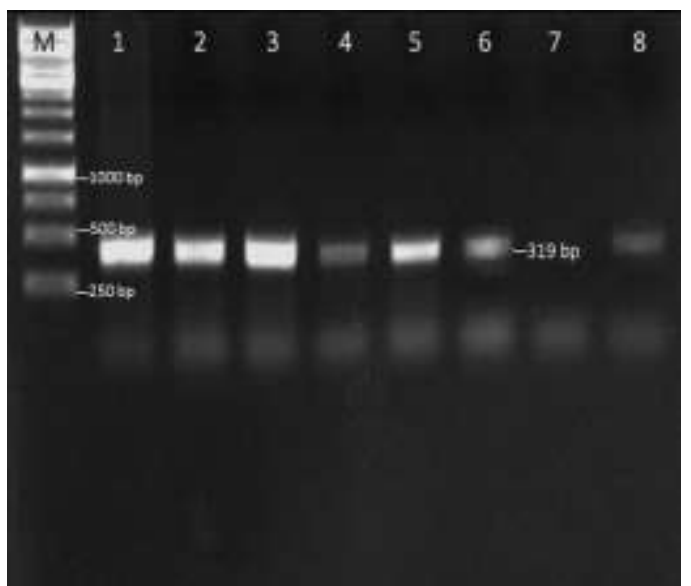

Fig. 2. Amplification of lytA from $S$. pneumoniae. M: DNA marker (1 Kbps); 1: positive control; 2, 3, 4, 5, 6 and 8: samples; 7: negative control. 


\section{Mosadegh M et al}

\section{Real-time assay}

Using real-time PCR, we identified both genes with low $\mathrm{Ct}$ values in all the isolates and culture-positive samples, in agreement with the conventional PCR results. A standard curve was obtained from $S$. pneumoniae ATCC 49619 (Fig. 3). The average $\mathrm{Ct}$ values of the blpA and lytA real-time PCR for culture-positive samples were 25.8 (18.8 to 34.2) and 24.6 (18.4 to 33.8), respectively (Fig. 4A). Two of the 57 (3.5\%) culture-negative samples were positive for $b l p A$, two $(3.5 \%)$ were positive for $l y t A$, and one of those samples was positive for both genes. $\mathrm{Ct}$ values were 32.8 and 34.1 for these two blpA culture-negative samples, (Fig. 4B), and 31.6 and 33.4 for the two lytA samples. The LODs for both blpA and lytA were determined to be $10 \mathrm{~S}$. pneumoniae cells per milliliter.

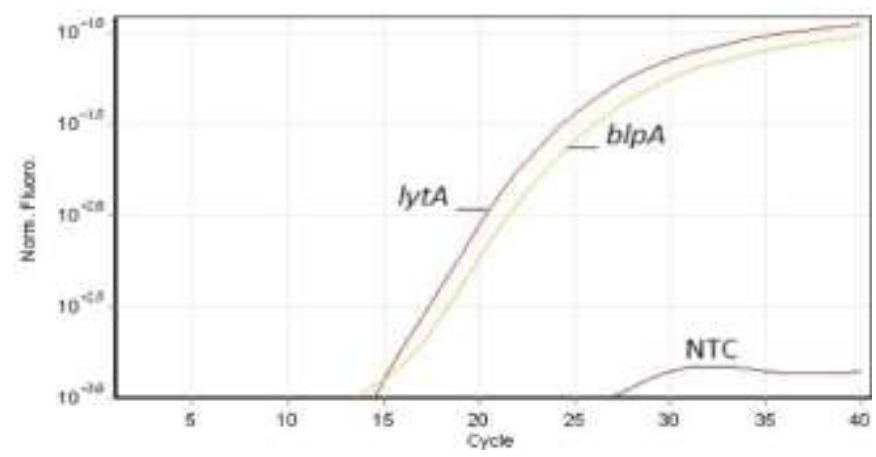

Fig. 3. Real-time PCR results of $l y t A$ and $b l p A$ from $S$. pneumoniae strain ATCC 49619.
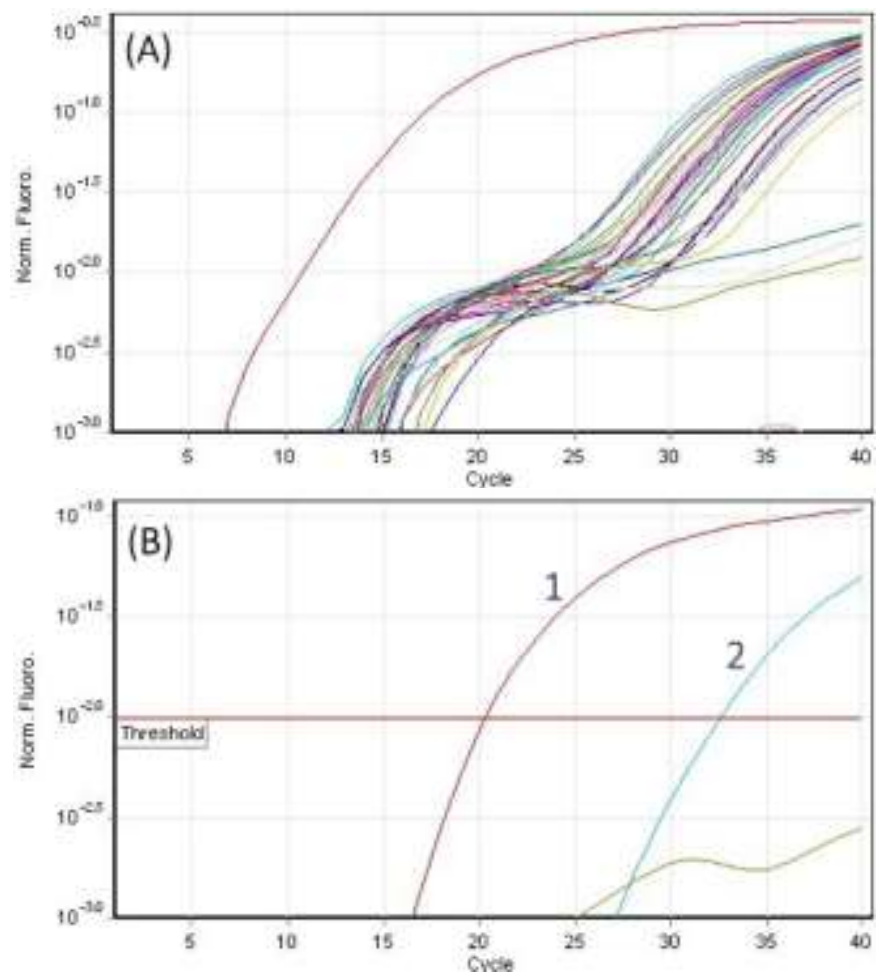

Fig. 4. Real-time PCR results for $b l p A$; A: clinical samples, B: number 1 is $b l p A$ from positive control, number 2 is $b l p A$ from one culturenegative sample, which gave a positive result in the PCR. 


\section{Discussion}

In our study, two isolates were resistant to optochin disk. This test is broadly used to differentiate pneumococcal isolates from other streptococci (13). Optochin-resistant $S$. pneumoniae isolates have been reported in previous investigations $(14,15,16)$. In most cases, resistance is due to point mutations in $a t p C$, which encodes an ATPase protein subunit (14, 17). The differentiation of $S$. pneumoniae from other related species is essential to choose the appropriate therapeutic strategies, due to the increasing resistance to penicillin and macrolides among pneumococcal and other closely-related species $(6,18)$. We demonstrated that the emergence of optochin-resistant isolates could disrupt the efficiency of conventional tests in diagnosing $S$. pneumoniae infections. The administration of antibiotics before sample collection, and activation of autolysins during sample transfer, can lead to false-negative results $(8,19,20)$. Recently, several molecular methods for diagnosis of pneumococcus in biological samples have been introduced by targeting $\operatorname{sod} A$, rpoA, spn9802, psaA, 16S rDNA, recA, piaA, tuf, ply, and lytA $(6,21)$. Although these molecular targets are useful for the detection of pneumococci, they are not able to differentiate $S$. pneumoniae from other closely-related species (12). In previous studies, false-positive results of lytA and false-negative results of ply and spn9802 have been shown $(20,22)$. Real-time PCR targeting lytA is currently recommended by the WHO for the detection of pneumococcal DNA in clinical specimens (22). Another diagnostic difficulty is related to the number of microorganisms present in clinical samples that may lead to false-negative results (23). In the present study, 57 culture-positive samples carrying $b l p A$ and $l y t A$ were detected using conventional and real-time PCR with low $\mathrm{Ct}$ values. There is a concordance between these two molecular methods and it has been demonstrated that both methods are sensitive for detection of pneumococcal DNA in culture-positive samples $(24,25)$. Our results revealed that the main difference between these two molecular methods was the ability to detect pneumococcal DNA in culture-negative samples. Using the real-time PCR, two of the 57 culture-negative samples were positive for both lytA and $b l p A$, while by conventional PCR, six culture-negative samples were positive for $b l p A$, seven for $l y t A$, and two of these were positive for both genes, indicating false-positive results. Considering the culture method as the gold standard for pneumococci detection, the sensitivity and specificity of conventional PCR for blpA were 100 and $89.47 \%$ and for $l y t A, 100$ and $87.71 \%$, respectively, while the sensitivity and specificity of real-time PCR for both genes were 100 and $96.49 \%$, respectively. The culture-negative samples that gave PCRpositive results were respiratory specimens, indicating that such specimens are not suitable for PCR-based pneumococcal detection methods. Previous studies have also shown that molecular methods are cannot distinguish between colonization and pneumococcal pneumonia (26). The molecular assays are also currently unable to substitute for traditional culture methods due to limitations in the simultaneous detection of multiple pathogens and antibiotic susceptibility (27). Nonetheless, real-time PCR is valuable for the direct detection of pneumococcus from clinical samples and molecular epidemiology studies (28).

Our results indicated that both molecular methods had high diagnostic sensitivity and can be used for the identification of $S$. pneumoniae directly on clinical samples from culturenegative patients but real-time PCR appears more specific than conventional PCR assay. In addition, respiratory secretions were found to be unreliable specimens for the identification of $S$. pneumoniae as they gave false-positive results by both methods.

\section{Acknowledgment}

This study was funded and supported by Tehran University of Medical Sciences (TUMS); (grant number 39370). The authors declare that they have no conflicts of interest. 


\section{References}

1. Usuf E, Bojang A, Hill PC, Bottomley C, Greenwood B, Roca A. Nasopharyngeal colonization of Gambian infants by Staphylococcus aureus and Streptococcus pneumoniae before the introduction of pneumococcal conjugate vaccines. New Microbes and New Infections. 2016;10:13-18.

2. Wahl B, O’Brien K, Greenbaum A, Liu L, Chu $\mathrm{Y}$, Majumder A, et al. Global, regional, and national burden of Streptococcus pneumoniae and Haemophilus influenzae type b disease in children in the era of conjugate vaccines: updated estimates from 2000-2015. Lancet Glob Health. 2018;6(7):e744-e757.

3. Esposito S, Terranova L, Patria MF, Marseglia GL, del Giudice MM, Bodini A, et al. Streptococcus pneumoniae colonization in children and adolescents with asthma: impact of the heptavalent pneumococcal conjugate vaccine and evaluation of potential effect of thirteen-valent pneumococcal conjugate vaccine. BMC infect dis. 2015;16:12.

4. Azarsa M, Moghadam SO, Rahbar M, Baseri Z, Pourmand MR. Molecular serotyping and genotyping of penicillin non-susceptible pneumococci: the introduction of new sequence types, Tehran, Iran. Microbes infect. 2019;32:100597.

5. Andam CP, Hanage WP. Mechanisms of genome evolution of Streptococcus. Infect Genet Evol. 2015;33:334-342.

6. Tam PYI, Hernandez-Alvarado N, Schleiss MR, Amy JY, Hassan-Hanga F, Onuchukwu C, et al. Detection of Streptococcus pneumoniae from culture-negative dried blood spots by real-time PCR in Nigerian children with acute febrile illness. BMC Res Notes. 2018;11(1):657.

7. Dunne EM, Tikkanen L, Balloch A, Gould K, Yoannes M, Phuanukoonnon S, et al. Characterization of 19A-like 19F pneumococcal isolates from Papua new Guinea and Fiji. Microbes Infect. 2015;7:86-8.

8. Yahiaoui RY, den Heijer CD, Wolfs $\mathrm{P}$, Bruggeman CA, Stobberingh EE. Evaluation of phenotypic and molecular methods for identification of Streptococcus pneumoniae. Future Microbiol. 2016;11(1):43-50.

9. Sakai F, Talekar SJ, Klugman KP, Vidal, JE. Expression of Streptococcus pneumoniae virulence-related genes in the nasopharynx of healthy children. PloS one. 2013;8(6):e67147.
10. Azarsa M, Salami SA, Pourmand MR, Forushani AR, Kazemian H. Evaluation of $l y t B$ Gene for Detection of Streptococcus pneumoniae in Isolates and Clinical Specimens by Real-Time PCR. Jundishapur Journal of Microbiology. 2017;10(6):e14378.

11. Suzuki N, Yuyama M, Maeda S, Ogawa H, Mashiko K, Kiyoura Y. Genotypic identification of presumptive Streptococcus pneumoniae by PCR using four genes highly specific for S. pneumoniae. J Med Microbiol. 2006;55(6):709-714.

12. Maria da Gloria SC, Tondella ML, McCaustland K, Weidlich L, McGee L, Mayer LW, et al. Evaluation and improvement of realtime PCR assays targeting lytA, ply, and psaA genes for detection of pneumococcal DNA. J Clin Microbiol. 2007;45(8):2460-2466.

13. Arbique JC, Poyart C, Trieu-Cuot P, Quesne G, Maria da Glória SC, Steigerwalt AG, et al. Accuracy of Phenotypic and Genotypic Testing for Identification of Streptococcus pneumoniae and Description of Streptococcus pseudopneumoniae sp. nov. J Clin Microbiol. 2004;42(10):4686-4696.

14. Pinto TC, Souza AR, de Pina SE, Costa NS, Neto AAB, Neves FP, et al. Phenotypic and molecular characterization of optochin-resistant Streptococcus pneumoniae isolates from Brazil, with description of five novel mutations in the atpC gene. J Clin Microbiol. 2013;51(10):3242-3249.

15. Pikis A, Campos JM, Rodriguez WJ, Keith, JM. Optochin resistance in Streptococcus pneumoniae: mechanism, significance, and clinical implications. J Infect Dis. 2001;184(5):582-590.

16. Raddaoui A, Tanfous FB, Achour W, Baaboura R, Hassen AB. Description of a novel mutation in the atpC gene in optochin-resistant Streptococcus pneumoniae strains isolates from Tunisia. International Journal of Antimicrobial Agents. 2018;51(5):803-805.

17. Robson RL, Essengue S, Reed NA, Horvat, RT. Optochin resistance in Streptococcus pneumoniae induced by frozen storage in glycerol. Diagnostic Microbiology and Infection Disease. 2007;58(2):185-190.

18. Ghahfarokhi SH, Mosadegh M, Ahmadi A, Pourmand MR, Azarsa M, Rahbar M, Nikmanesh B. Serotype Distribution and antibiotic 
susceptibility of Streptococcus pneumoniae isolates in Tehran, Iran: A surveillance study. Infect Drug Resist. 2020;13:333-340.

19. Khater WS, Elabd SH. Identification of common bacterial pathogens causing meningitis in culture-negative cerebrospinal fluid samples using real-time polymerase chain reaction. Int $\mathbf{J}$ Microbiol. 2016;2016:4197187.

20. Abdeldaim GM, Stralin K, Olcén P, Blomberg J, Herrmann B. Toward a quantitative DNA-based definition of pneumococcal pneumonia: a comparison of Streptococcus pneumoniae target genes, with special reference to the Spn9802 fragment. Diagnostic Microbiology and Infection Disease. 2008;60(2):143-150.

21. Satzke C, Turner P, Virolainen-Julkunen A, Adrian PV, Antonio M, Hare KM, et al. Standard method for detecting upper respiratory carriage of Streptococcus pneumoniae: updated recommendations from the World Health Organization Pneumococcal Carriage Working Group. Vaccine. 2013;32(1):165-179.

22. Simões AS, Tavares DA, Rolo D, Ardanuy C, Goossens $\mathrm{H}$, Henriques-Normark $\mathrm{B}$, et al. lytAbased identification methods can misidentify Streptococcus pneumoniae. Diagnostic microbiology and infectious disease. 2016;85(2):141-8.

23. Shahinas D, Tamber GS, Arya G, Wong A, Lau R, Jamieson F, et al. Whole-genome sequence of Streptococcus pseudopneumoniae isolate IS7493. J Bacteriol. 2011;193:6102-6103.
24. Wessels E, Schelfaut JJ, Bernards AT, Claas E.C. Evaluation of several biochemical and molecular techniques for identification of Streptococcus pneumoniae and Streptococcus pseudopneumoniae and their detection in respiratory samples. Journal of clinical microbiology. 2012;50(4):1171-7.

25. Xu Q, Kaur R, Casey JR, Adlowitz DG, Pichichero ME, Zeng M. Identification of Streptococcus pneumoniae and Haemophilus influenzae in culture-negative middle ear fluids from children with acute otitis media by combination of multiplex PCR and multi-locus sequencing typing. Int J Pediatr Otorhinolaryngol. 2011;75(2):239-244.

26. Murdoch DR, Anderson TP, Beynon KA, Chua A, Fleming AM, Laing RT, et al. Evaluation of a PCR assay for detection of Streptococcus pneumoniae in respiratory and nonrespiratory samples from adults with community-acquired pneumonia. J Clin Microbiol. 2003;41(1):63-66. 27. Diawara I, Katfy K, Zerouali K, Belabbes H, Elmdaghri N. A duplex real-time PCR for the detection of Streptococcus pneumoniae and Neisseria meningitidis in cerebrospinal fluid. $\mathbf{J}$ Infect Dev Ctries. 2016;10(1):53-61.

28. Wang Y, Guo G, Wang H, Yang X, Shao F, Yang $\mathrm{C}$, et al. Comparative study of bacteriological culture and real-time fluorescence quantitative PCR (RT-PCR) and multiplex PCR-based reverse line blot (mPCR/RLB) hybridization assay in the diagnosis of bacterial neonatal meningitis. BMC pediatr. 2014;14:224. 